\title{
CalibETH: AN INTERACTIVE COMPUTER PROGRAM FOR THE CALIBRATION OF RADIOCARBON DATES
}

\author{
THOMAS R. NIKLAUS, GEORGES BONANI, MARKUS SIMONIUS, MARTIN SUTER ${ }^{I}$ and \\ WILLY WÖLFLI
}

\author{
Institut für Mittelenergiephysik, ETH-Hönggerberg, CH-8093 Zürich, Switzerland
}

\begin{abstract}
A computer program for convenient calibration of radiocarbon dates has been developed. The program has a simple user interface, which includes pull-down menus, windows and mouse support. All important information, such as calibration curves, probability density function and results, in text form, are displayed on the screen and easily can be rearranged by the user. Two versions of CalibETH, one for an IBM-PC and one for the Macintosh, are available. CalibETH runs under the graphics interface, GEM, from Digital Research, on an IBM PC.
\end{abstract}

\section{INTRODUCTION}

The fluctuation of ${ }^{14} \mathrm{C}$ concentration in the atmosphere complicates the conversion of a radiocarbon age into a calendar age. This fluctuation results in a probability density function along the calendarage time scale. In general, an interactive analysis of this distribution is necessary to obtain reliable results. CalibETH, a new program for probabilistic calibration of radiocarbon dates, was designed to run under a simple graphics user interface. Versions were developed for Macintosh as well as for IBM PCs, differing only slightly. GEM-Desktop (Digital 1988) was chosen for an IBM PC as a graphics user interface. Some computer programs have already implemented the procedure for probabilistic calibration (Pazdur \& Michczynska 1989; van der Plicht \& Mook 1989; Stuiver \& Reimer 1986). The mathematical procedures, which underlie CalibETH, are based on published algorithms for radiocarbon age calibration (Michczynska, Pazdur \& Walanus 1990; Mook 1983; Mook, Hasper \& van der Plicht 1987; Reimer \& Stuiver 1987).

\section{USER INTERFACE}

We employed the graphics user interface (GUI) procedure to obtain a user-friendly calibration program for radiocarbon dates. The user is led through the program by means of pull-down menus, which can be chosen easily and quickly with a mouse. If a command is not known or has been forgotten, it can be found quickly in the menu bar. "Hot-keys" are available for the most frequently used commands. Further commands are self-explanatory but the manual should be consulted for advanced options. Again, the menu bar helps in locating these commands. Program outputs are displayed in various windows, as text or in graphics format. Figure 1 shows a typical screen with various windows. The windows can be resized, sections may be enlarged, and text windows can be scrolled over their contents. All important information, such as input date, the applied calibration curve, confidence levels and o ranges, are displayed in the Results window. This information can be printed or stored in a data file.

The following graphics windows are produced by CalibETH:

The Calibration window contains the section of the calibration curve to be used. The Cumulative window shows the cumulative probability distribution and the median with the $1 \sigma(68.26 \%)$ and $2 \sigma(95.44 \%)$ error range. The probability density function is displayed in the Probability window together with the $1 \mathrm{o}$ and $2 \mathrm{o}$ confidence levels. The same information is displayed as a histogram

${ }^{1}$ Paul Scherrer Institut, c/o Institut für Mittelenergiephysik, ETH-Hönggerberg, CH-8093 Zürich, Switzerland 
File Window Control Input Setup Edit Q9
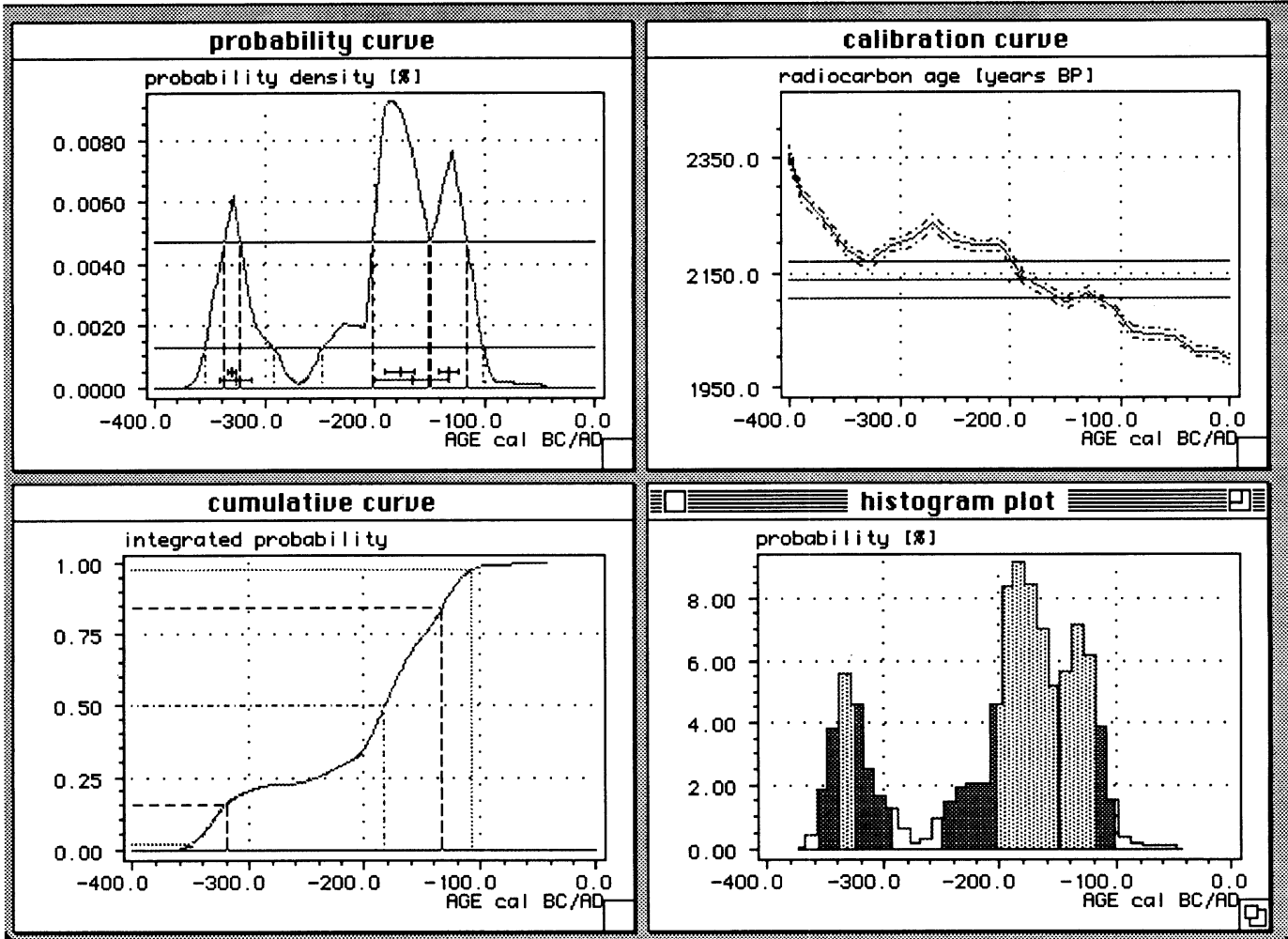

Fig. 1. A typical screen dump of the program CalibETH, shown with four graphics windows, which include probability density function, a section of the calibration curve, cumulative probability and the histogram. Note, the negative part of the mathematical calendar axis has to be shifted by one year in order to agree with the dendrochronological calendar (e.g., $0=1 \mathrm{cal} \mathrm{BC}$, or $99=100 \mathrm{cal} \mathrm{BC}$ ).

in the Histogram window. The graphics can be enlarged or reduced and all sections can be zoomed. All graphics windows always show the same calendar age range. The graphics can be printed as well as stored in several file formats. Possible file formats are: HPGL (Hewlett Packard graphics language), RTF-PICT (Microsoft Rich Text Format) and ShowETH input file. With the graphics program, ShowETH, a subsequent treatment of the graphics is possible.

All inputs are handled by dialog boxes, which call immediate attention to incorrect inputs and ask for a new definition. The actual state of the program, all the configuration parameters, and the disposition of the window, are stored when exiting the program. Thus, the program is guaranteed to continue at the position where it was exited.

CalibETH is written in Modula-2 (Wirth 1988). To access the graphics user interface, the Modula-2 library, DialogMachine, which was developed at the ETH (Fischlin 1986; Keller 1989), is used. On the IBM PC, the Modula-2 implementation from JPI (TopSpeed 1990) with the graphics user interface, GEM (Digital 1988), and on the Macintosh, the Modula-2 implementation from the ETH (Wirth et al. 1989) are used. 


\section{CALIBRATION PROCEDURE}

The mathematical procedure presented here has already been published (Michczynska, Pazdur \& Walanus 1990), but the implementation differs in the various programs (Aitchison et al. 1989). The entire probabilistic calibration procedure can be explained with the probability theory and the Bayes theorem (Bayes 1958; Eadie et al. 1971). The following notations are used:

$\mathrm{m} \pm \delta=$ measured radiocarbon age and standard deviation

$\mathrm{W}=$ true radiocarbon age corresponding to $\mathrm{m}$

$\mathrm{A}=$ calendar age

$\mathrm{c}(\mathrm{A})=$ measured calibration curve (radiocarbon age $v$ s. calendar age, $\mathrm{A}$ )

$\sigma_{c}(A)=$ standard deviation of measured points in the calibration curve

$\mathrm{p}(\mathrm{a} \mid \mathrm{b})=$ probability density function of $\mathrm{a}$ for given, $\mathrm{b}$

$$
<\mathrm{a}>=\int \mathrm{a} p(\mathrm{a} \mid \mathrm{b}) \mathrm{da}, \text { with } \int \mathrm{p}(\mathrm{a} \mid \mathrm{b}) \mathrm{da}=1
$$

$\mathrm{p}_{\mathrm{o}}(\mathrm{a} \mid \mathrm{b})=$ Gaussian probability density function.

Statistically, the measure ${ }^{14} \mathrm{C}$ age, as well as the measured points of the calibration curve, can be considered a probability density function:

- distribution of measured radiocarbon age, $\mathrm{m}$, given that its true value is $\mathrm{W}$

$$
\mathrm{p}^{\mathrm{M}}(\mathrm{m} \mid \mathrm{W})=\mathrm{p}_{\delta}(\mathrm{m} / \mathrm{W})=\frac{1}{\sqrt{2 \pi} \delta} \mathrm{e}^{-\frac{(\mathrm{m}-\mathrm{W})^{2}}{2 \delta^{2}}}
$$

- distribution of true radiocarbon age, $\mathrm{W}$, for given calendar age, $\mathrm{A}$

$$
\mathrm{p}^{\mathrm{C}}(\mathrm{W} \mid \mathrm{A})=\mathrm{p}_{\mathrm{o}_{\mathrm{c}}(\mathrm{A})}(\mathrm{W} \mid \mathrm{c}(\mathrm{A})) \text {. }
$$

The probability density function $\mathrm{p}^{\mathrm{MC}}(\mathrm{m} \mid \mathrm{A})$ of $\mathrm{m}$ for given calendar age, $\mathrm{A}$, can then be calculated by folding $\mathrm{p}^{\mathrm{M}}$ and $\mathrm{p}^{\mathrm{C}}$

$$
\begin{aligned}
\mathrm{p}^{\mathrm{MC}}(\mathrm{m} \mid \mathrm{A}) & =\int \mathrm{p}^{\mathrm{M}}(\mathrm{m} \mid \mathrm{W}) \mathrm{p}^{\mathrm{C}}(\mathrm{W} \mid \mathrm{A}) \mathrm{dW} \\
& =\int \mathrm{p}_{\delta}(\mathrm{m} \mid \mathrm{W}) \mathrm{p}_{\mathrm{o}_{\mathrm{c}}(\mathrm{A})}(\mathrm{W} \mid \mathrm{c}(\mathrm{A})) \\
& =\mathrm{p}_{\sigma(A)}(\mathrm{m} \mid \mathrm{c}(\mathrm{A})), \text { with } \sigma(A)=\sqrt{\delta^{2}+\sigma_{c}(A)^{2}} .
\end{aligned}
$$

The Bayes theorem (Eq. 2) (Bayes 1958; Michczynska, Pazdur \& Walanus 1990; Eadie et al. 1971) links the probability density function for $\mathrm{m}$ to the probability density for $\mathrm{A}$

$$
\begin{aligned}
\text { Bayes theorem: } & p(a \mid b)=\frac{p(b \mid a) h(a)}{\int_{p} p(b \mid a) h(a) d a} \\
h(a): \quad \text { represents the a priori knowledge or degree of belief. } & \text {. }
\end{aligned}
$$

One can write the probability density function of $\mathrm{A}$ for given, $\mathrm{m}$, using Bayes' theorem. Taking the degree of belief $\mathrm{h}(\mathrm{a})$ to be constant over the range of $\mathrm{A}$, where $\mathrm{p}^{\mathrm{MC}}(\mathrm{m} / \mathrm{a})$ does not significantly differ from 0 (typically 300 years), the calendar age probability density function is 


$$
\mathrm{p}^{\mathrm{A}}(\mathrm{a} \mid \mathrm{m})=\frac{\mathrm{p}^{\mathrm{MC}}(\mathrm{m} \mid \mathrm{a})}{\int_{-\infty}^{\infty} \mathrm{p}^{\mathrm{MC}}(\mathrm{m} \mid \mathrm{a}) \mathrm{da}} .
$$

\section{Procedure implementation}

The various published calibration programs differ in implementation of the calibration procedure: the algorithm used for the integration; the selection of the integration range; and the interpolation of the calibration points. CalibETH integrates the normalization part of the probability density function (Eq. 6) in one-year steps. Because of the seasonal fluctuations of the ${ }^{14} \mathrm{C}$ concentration in the atmosphere, it is not advisable to use shorter integration steps.

The probability density function can be calculated in arbitrary year resolution ( $R$ in years). In this case, a mean value over the resolution width of the probability density function (Eq. 6) is calculated (Eq. 7)

$$
\overline{\mathrm{p}^{\mathrm{A}}(\mathrm{a} \mid \mathrm{m})}=\sum_{\mathrm{i}=0}^{\mathrm{R}-1} \frac{\mathrm{p}^{\mathrm{A}}\left(\left[\mathrm{a}-\frac{\mathrm{R}-1}{2}+\mathrm{i}\right] \mid \mathrm{m}\right)}{\mathrm{R}} .
$$

The one-year resolution should be preferred for high-precision ${ }^{14} \mathrm{C}$ dates. The cumulative probability density function is calculated simultaneously with the same resolution

$$
P^{A}(a \mid m)=\int_{-\infty}^{a} p^{A}\left(a^{\prime} \mid m\right) d a^{\prime}
$$

When building the calibration curve, a linear interpolation between individual measured values is used. The following options are available to estimate the uncertainty of the calibration curve:

- constant error of the calibration curve $\left(\sigma_{0}^{2}=\right.$ typical curve error $)$

- linear interpolation of the standard errors in the calibration curve

- squared interpolation of the standard errors in the calibration curve

$$
\sigma_{c}(A)^{2}=\sigma_{c}\left(A_{i}\right)^{2}+\frac{\sigma_{c}\left(A_{i+1}\right)^{2}-\sigma_{c}\left(A_{i}\right)^{2}}{A_{i+1}-A_{i}}\left(A-A_{i}\right) .
$$

The intercepts of $m \pm$ no with the calibration curve, $(\mathrm{c}(\mathrm{A}))$, establish the boundaries for the integration, $\left(\sigma=\sqrt{\delta^{2}+\sigma_{0}^{2}},\left(\sigma_{0}=\right.\right.$ standard curve error $\left.)\right)$. [n] can be chosen by the user but should fulfill the condition, $[3 \leq n \leq 6]$. For greater [n], the performance (speed) of the program will be reduced. Moreover, it is possible to define an explicit integration range. Often, a histogram bar plot is more convenient than plotting the probability density function. For cases like these, CalibETH provides a histogram with a user-defined bar width. In addition, the confidence levels $(1 \sigma, 2 \sigma$ and user-defined), with corresponding ranges and frequency, are calculated from the probability density function (Reimer \& Stuiver 1987). The weighted average (Eq. 1) and the standard deviation for all ranges are calculated. All intercepts of the radiocarbon age with the calibration curve $(\mathrm{m}=$ $c(A)$ ), as well as the weighted average with the standard deviation of the distribution, are estimated. From the cumulative probability (Eq. 8), the $1 \sigma, 2 \sigma$ and user-defined range are calculated (e.g., $1 \sigma$ boundaries: $\left.\mathrm{P}^{\mathrm{A}}(\mathrm{a} \mid \mathrm{m})=0.16, \mathrm{P}^{\mathrm{A}}(\mathrm{a} \mid \mathrm{m})=0.84\right)$. In order to control the calculations, the following parameters can be varied: resolution of probability density function; histogram width; user-defined 
confidence level; sigma factor to fix the integration boundaries; standard error of calibration curve; interpolation of the calibration curve; interpolation of the standard deviation of the calibration curve. It is also possible to handle new data sets of calibration curves by CalibETH.

\section{CALIBRATION EXAMPLE}

After starting CalibETH, the last configuration is read from the disk. CalibETH is now in the same state as in the preceding session. By selecting the command, input record, in the menu, INPUT, the program is ready for reading the dates $(\mathrm{m} \pm \delta)$ of the sample to be calibrated (Fig. 2). The sample used is one of the Dead Sea scrolls (ETH-6639 DSS3) published in this issue (Bonani et al. 1992) with a conventional radiocarbon age of $2139 \pm 32 \mathrm{BP}$. The user always has the option to change the program parameters in the SETUP menu. All modifications are valid until they are changed again, even after an interruption in the program. The calibration starts with the command, calculate, of the CONTROL menu. CalibETH defines the boundaries for the integration along the calendar age by finding the intercepts of $2139 \pm$ no BP with the calibration curve $\left(\sigma=\sqrt{\delta^{2}+\sigma_{0}^{2}}=\sqrt{32^{2}+15^{2}}\right)$. $\mathrm{n}$ is the user-defined sigma multiplier. With $\mathrm{n}=3$ and $\sigma_{0}=15$, the boundaries are $(373 \mathrm{cal} \mathrm{BC}, 45$ cal $\mathrm{BC}$ ). After the calculation, the results are displayed and can be printed or written on disk. We followed van der Plicht and Mook (1989) in the discussion of a calibrated date. From the cumulative probability (Fig. 3), a median $\overline{\mathrm{A}}\left(\mathrm{P}^{\mathrm{A}}(\mathrm{a} \mid \mathrm{m})=0.5\right)$ with an error range of $68 \%$ can be extracted. According to van der Plicht, this makes sense only if the probability density function has a shape with only one bump. In this case, the weighted average (Eq. 1) can also be discussed. CalibETH offers information on median and weighted average, which are, for our sample

$$
\text { median }=183_{-137}^{+45} \mathrm{cal} \mathrm{BC}
$$

weighted average $=203 \pm 75 \mathrm{cal} \mathrm{BC}$

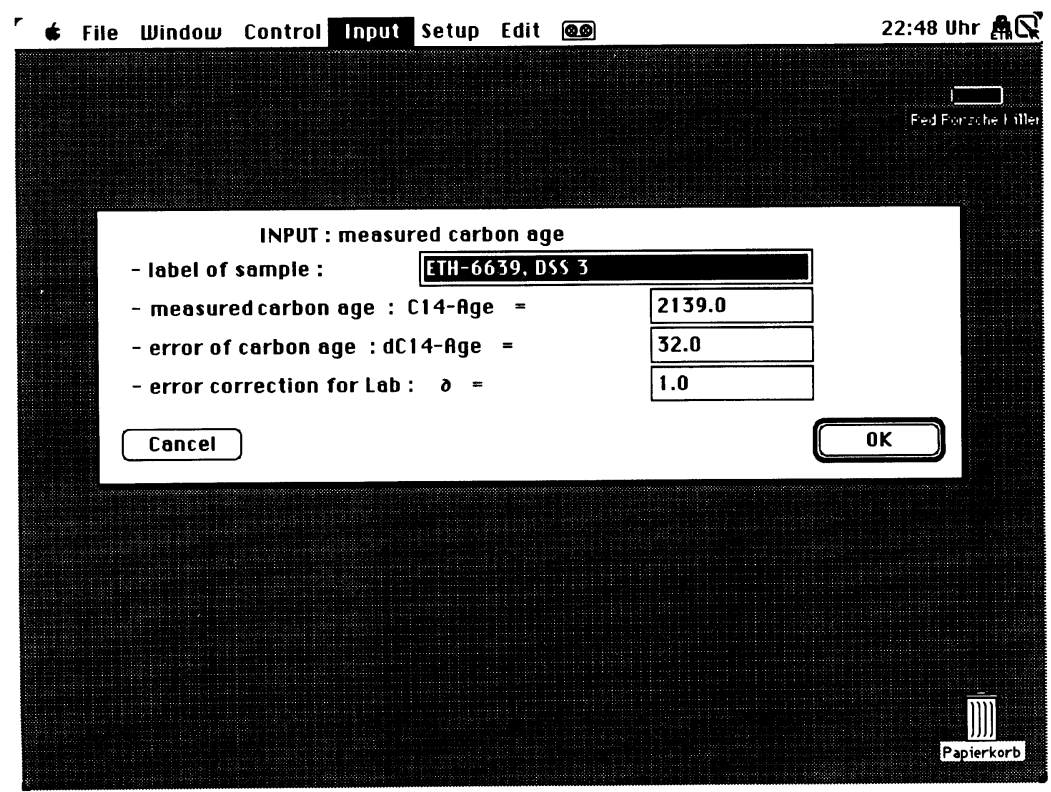

Fig. 2. User-friendly input dialog box for reading the conventional radiocarbon date 


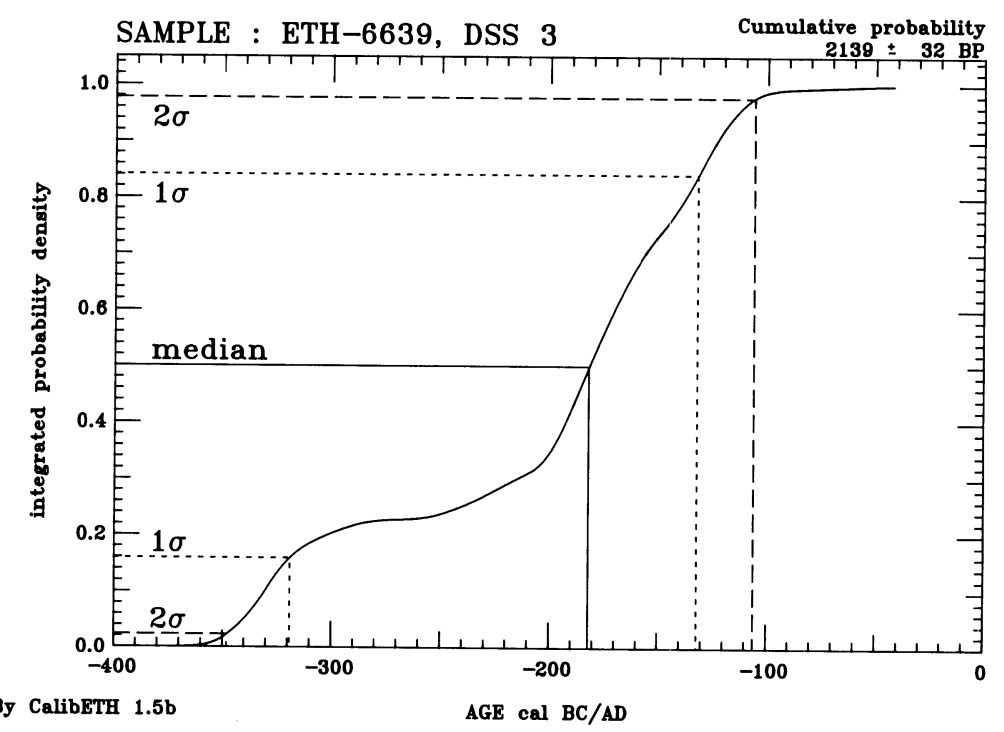

Fig. 3. Cumulative probability distribution of sample ETH-6639 (2139 $\pm 32 \mathrm{BP})$ with median and $1 \sigma / 2 \sigma$ ranges

The probability density function (Fig. 4) shows that the conditions mentioned above are not fulfilled, and therefore, the probability density function has to be analyzed. CalibETH follows the procedure of Reimer and Stuiver (1987). The confidence levels for $1 \sigma(68.26 \%), 2 \sigma(95.44 \%)$, and a limit defined by the user, specify the corresponding calendar age ranges of the calibration. They are plotted in the probability graph (Fig. 4), and are marked as filled areas in the histogram (Fig. 5). Table 1 also shows the probability and the weighted average of each range.

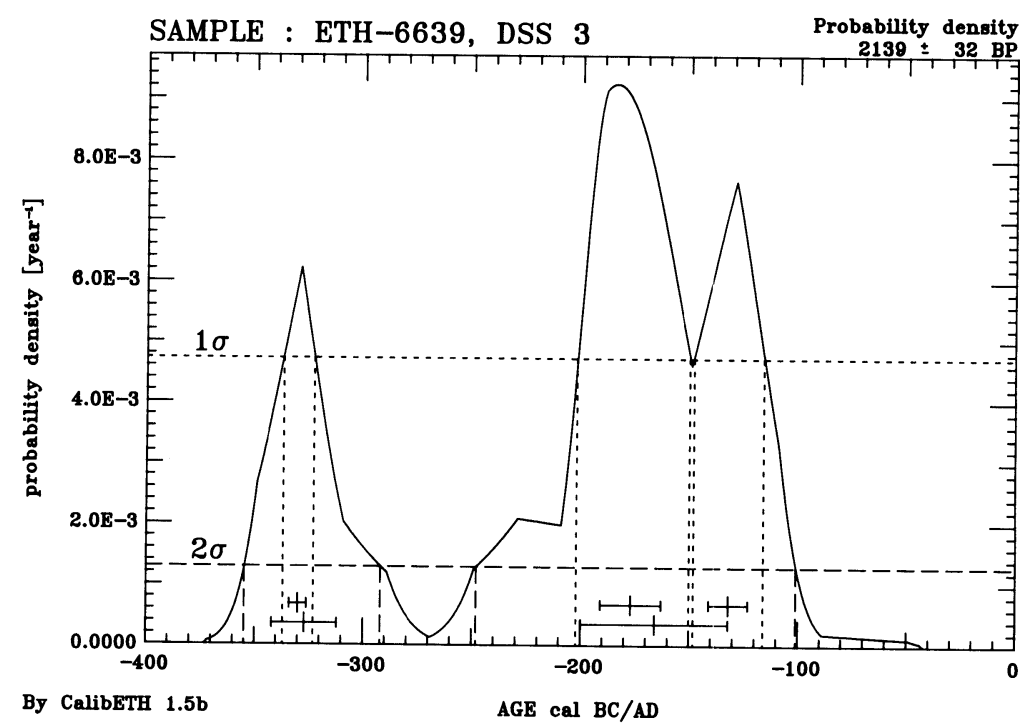

Fig. 4. Probability density function of sample ETH-6639 (2139 \pm 32 BP) with corresponding $1 \sigma$ and $2 \sigma$ confidence levels 


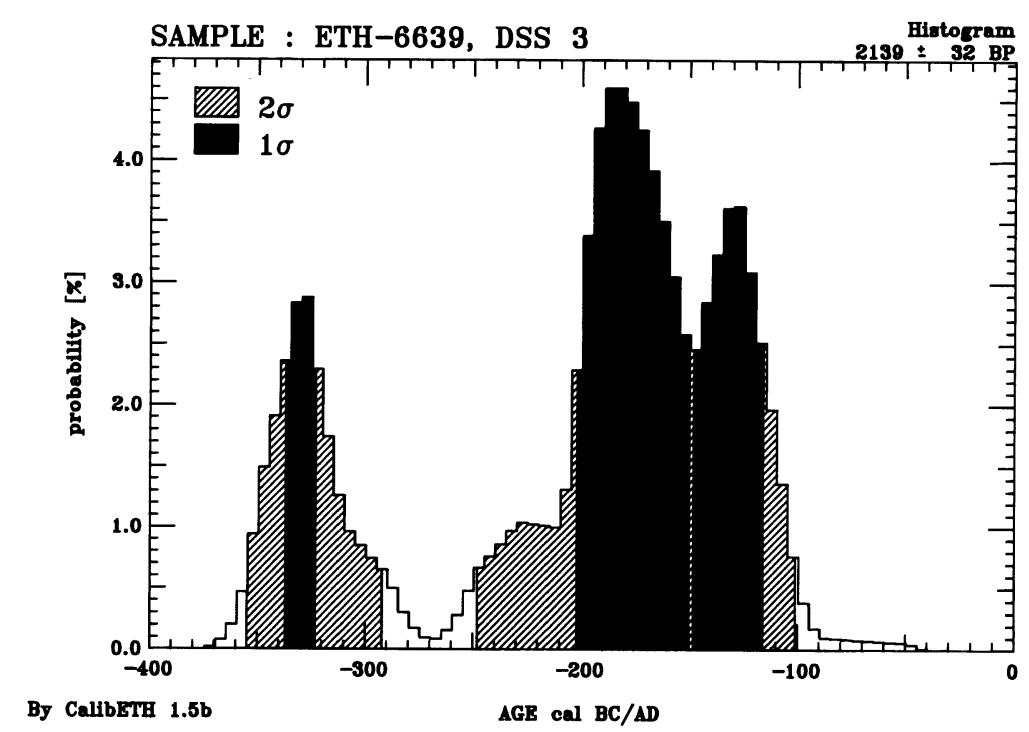

Fig. 5. Histogram of the probability density function of sample ETH- $6639(2139 \pm 32 \mathrm{BP})$ with corresponding $1 \sigma$ and $2 \sigma$ ranges

\section{COMPARISON OF CALIBRATION METHODS}

To test the performance of CalibETH, we compared its results with those of the following calibration programs:

CAL4/Groningen - Version November 1988, van der Plicht and Mook (1989)

Calib/Gliwice - Version 4.0 September 1989, Pazdur and Michczynska (1989)

Calib/Seattle _ - Revision $2.0 /$ 1987, Stuiver and Reimer (1986)

The samples listed in Table 2 are used for the comparison. Van der Plicht and Mook (1989) used sample GrN-14980 in their discussion, and reported additional results to the standard output of CAL4. In Dubrovnik 1988, Aitchison et al. (1989) made a comparison of calibration methods, and sample GrN-6483 was used to compare a single date calibration.

TABLE 1. Confidence Levels of Sample ETH-6639

\begin{tabular}{|c|c|c|c|}
\hline & Range* & Probability & Weighted average \\
\hline \multirow[t]{3}{*}{1 o: } & $338-324 \mathrm{cal} \mathrm{BC}$ & $(11.9 \%)$ & $331 \mathrm{cal} \mathrm{BC}$ \\
\hline & $203-151 \mathrm{cal} \mathrm{BC}$ & $(58.4 \%)$ & $178 \mathrm{cal} \mathrm{BC}$ \\
\hline & $149-117$ cal BC & $(29.7 \%)$ & $133 \mathrm{cal} \mathrm{BC}$ \\
\hline \multirow[t]{2}{*}{$2 \sigma:$} & $356-293 \mathrm{cal} \mathrm{BC}$ & $(21.7 \%)$ & $328 \mathrm{cal} \mathrm{BC}$ \\
\hline & $249-102 \mathrm{cal} \mathrm{BC}$ & $(78.3 \%)$ & $167 \mathrm{cal} \mathrm{BC}$ \\
\hline
\end{tabular}

*Ranges calculated from probability density function 
TABLE 2. Comparison Data

\begin{tabular}{|c|c|c|c|c|c|}
\hline Sample no. & Age & $\sigma$ & Site & Context & Reference \\
\hline GrN-6483 & $4790 \mathrm{BP}$ & 40 & Niederwil & Carbonized grain & Lanting \& Mook (1971) \\
\hline GrN-14980 & $2365 \mathrm{BP}$ & 45 & \multicolumn{2}{|c|}{ Satricum BII/3570 } & van der Plicht, Mook \& \\
\hline ETH-6645 & $1892 \mathrm{BP}$ & 32 & Murrabba'a & $\begin{array}{l}\text { Dead Sea scroll } \\
\left(\mathrm{AD} 134^{*}\right)\end{array}$ & $\begin{array}{l}\text { Hasper (1989) } \\
\text { Bonani et al. (1992) }\end{array}$ \\
\hline
\end{tabular}

*Paleographic age of sample

All programs should use the same configuration. Because CAL4 uses a 3 o integration range, the other programs have to be set up to the same value, if possible. In all the programs, the calibration data points of Stuiver and Pearson (1986, AD 1950-2500 BC) were used. Where needed to extend the calibration range, data points from Pearson et al. (1986) were added. Table 3 shows the calibration results of dates obtained by these four programs. Calib/Seattle, CAL4 and CalibETH calculate the confidence levels from the probability density function. The ranges are in good agreement. All the results of Calib/Seattle and CalibETH are the same or differ only by one year. The reasons for these deviations are: 1) the error of the calibration curve may be interpolated differently (ignored, constant error, next neighbor); 2) the values of the o limits may differ (68\%, $68.26 \%$ ); 3) rounding effects. In addition, van der Plicht and Mook (1989) use a cubic spline function instead of a straight line between the calibration points. The probabilities for each range also agree well, even though the peak analysis of sample GrN-14980 by van der Plicht and Mook (1989) are compared with the 3 o ranges of CalibETH.

The median and the corresponding o ranges from the cumulative probability are calculated by Calib/Gliwice, CalibETH and, in some cases, also by CAL4. These results differ only by a few years, usually less than five, which can be explained by the reasons discussed above. In addition, Calib/Gliwice fixes the integration boundaries differently than CalibETH. In summary, CalibETH agrees well with the existing programs.

\section{CONCLUSION}

CalibETH is a calibration program with a simple user interface. It offers to the user a complete set of information. The results, as far as they can be compared, are in good agreement with the results of the other calibration programs. The described version of CalibETH can handle the calibration of a single date. A new version, which will include the calibration of a set of related or arbitrary dates, along with the automated calibration process, is in preparation.

\section{ACKNOWLEDGMENT}

Part of this work was supported by the Swiss National Science Foundation. 
TABLE 3. Summary of calibrations from various programs. For layout reasons, the word "cal" is omitted, and the ages are stated as $A D / B C$ values instead of cal $A D / B C$.

\begin{tabular}{|c|c|c|c|c|c|}
\hline \multicolumn{2}{|l|}{$\begin{array}{l}\text { Program } \\
\text { descriptor }\end{array}$} & $\begin{array}{c}\text { CalibETH } \\
\text { Niklaus }\end{array}$ & $\begin{array}{l}\text { CALIB } \\
\text { Stuiver }\end{array}$ & $\begin{array}{c}\text { Cal4 } \\
\text { van der Plicht }\end{array}$ & $\begin{array}{l}\text { CALIB } \\
\text { Pazdur }\end{array}$ \\
\hline \multicolumn{2}{|l|}{ Sample } & \multicolumn{4}{|c|}{ GrN-6483 / 4790 $\pm 40 \mathrm{BP}$} \\
\hline \multicolumn{2}{|l|}{ Weighted average } & $3575 \pm 66 \mathrm{BC}$ & & & \\
\hline \multicolumn{2}{|l|}{ Median } & $3574 \mathrm{BC}$ & & $3567 \mathrm{BC}^{*}$ & $3572 \mathrm{BC}$ \\
\hline \multirow{2}{*}{\begin{tabular}{|c|} 
Confidence ranges \\
calculated from \\
probability density \\
with \\
probabilities \\
\end{tabular}} & $68.26 \%$ & $\begin{array}{l}3642-3605 \mathrm{BC}(33.9 \%) \\
3585-3519 \mathrm{BC}(66.1 \%)\end{array}$ & $\begin{array}{l}3642-3605 B C(34 \%) \\
3585-3519 B C(66 \%)\end{array}$ & $\begin{array}{l}3638-3610 \mathrm{BC} \\
3582-3520 \mathrm{BC}\end{array}$ & \\
\hline & $94.44 \%$ & $\begin{array}{l}3692-3505 \mathrm{BC}(95.5 \%) \\
3404-3385 \mathrm{BC}(4.5 \%)\end{array}$ & $\begin{array}{l}3692-3505 \mathrm{BC}(96 \%) \\
3403-3385 \mathrm{BC}(4 \%) \\
\end{array}$ & $\begin{array}{l}3690-3662 \mathrm{BC} \\
3650-3508 \mathrm{BC} \\
3404-3386 \mathrm{BC} \\
\end{array}$ & \\
\hline $\begin{array}{c}\text { Confidence ranges } \\
\text { calculated from } \\
\text { cumulative } \\
\text { probability } \\
\end{array}$ & $\begin{array}{l}50.00 \% \\
68.26 \% \\
95.44 \% \\
98.00 \%\end{array}$ & $\begin{array}{l}3624-3540 \mathrm{BC} \\
3637-3527 \mathrm{BC} \\
3685-3393 \mathrm{BC} \\
3691-3389 \mathrm{BC} \\
\end{array}$ & & $3629-3526 \mathrm{BC}^{*}$ & $\begin{array}{l}3621-3542 \mathrm{BC} \\
3675-3394 \mathrm{BC} \\
3687-3388 \mathrm{BC}\end{array}$ \\
\hline \multicolumn{2}{|c|}{ Sample } & \multicolumn{4}{|c|}{ GrN-14980 / 2365 \pm 45 BP } \\
\hline \multicolumn{2}{|l|}{ Weighted average } & $501 \pm 109 \mathrm{BC}$ & & & \\
\hline \multicolumn{2}{|l|}{ Median } & $469 \mathrm{BC}$ & & & $464 \mathrm{BC}$ \\
\hline \multirow{3}{*}{$\begin{array}{c}\text { Confidence ranges } \\
\text { calculated from } \\
\text { probability density } \\
\text { with } \\
\text { probabilities }\end{array}$} & $68.26 \%$ & $511-393 \mathrm{BC}(100 \%)$ & $511-393 \mathrm{BC} \quad(100 \%)$ & $\begin{array}{l}518-426 \mathrm{BC} \\
418-392 \mathrm{BC} \\
\end{array}$ & \\
\hline & $94.44 \%$ & $\begin{array}{ll}760-683 \mathrm{BC} & (15.3 \%) \\
656-640 \mathrm{BC} & (1.2 \%) \\
549-375 \mathrm{BC} & (83.5 \%) \\
\end{array}$ & $\begin{array}{ll}760-682 \mathrm{BC} & (16 \%) \\
657-639 \mathrm{BC} & (1 \%) \\
549-375 \mathrm{BC} & (83 \%) \\
\end{array}$ & $\begin{array}{l}760-688 \mathrm{BC} \\
656-638 \mathrm{BC} \\
546-380 \mathrm{BC} \\
\end{array}$ & \\
\hline & $\begin{array}{c}99.70 \% \\
\text { peak }^{* *} \\
\text { analyse }\end{array}$ & $\begin{array}{ll}764-674 \mathrm{BC} & (15.3 \%) \\
665-622 \mathrm{BC} & (2.0 \%) \\
603-368 \mathrm{BC} & (82.4 \%) \\
& \\
273-267 \mathrm{BC} & (0.2 \%) \\
\end{array}$ & & $\begin{array}{ll}760-675 \mathrm{BC}^{\dagger} & (16 \%) \\
675-620 \mathrm{BC}^{\dagger} & (2 \%) \\
610-560 \mathrm{BC}^{\dagger} & (1 \%) \\
560-360 \mathrm{BC}^{\dagger} & (80 \%) \\
275-275 \mathrm{BC}^{\dagger} & (1 \%) \\
\end{array}$ & \\
\hline $\begin{array}{l}\text { Confidence ranges } \\
\text { calculated from } \\
\text { cumulative } \\
\text { probability } \\
\end{array}$ & $\begin{array}{l}50.00 \% \\
68.26 \% \\
95.44 \% \\
98.00 \% \\
\end{array}$ & $\begin{array}{l}519-423 \mathrm{BC} \\
655-408 \mathrm{BC} \\
748-389 \mathrm{BC} \\
753-379 \mathrm{BC} \\
\end{array}$ & & $675-415 \mathrm{BC}^{\dagger}$ & $\begin{array}{l}512-420 \mathrm{BC} \\
744-389 \mathrm{BC} \\
750-379 \mathrm{BC} \\
\end{array}$ \\
\hline \multicolumn{2}{|l|}{ Sample } & \multicolumn{4}{|c|}{ ETH-6645 / $1892 \pm 32$ BP } \\
\hline \multicolumn{2}{|l|}{ Weighted average } & $111 \pm 41 \mathrm{AD}$ & & & \\
\hline \multicolumn{2}{|l|}{ Median } & $105 \mathrm{AD}$ & & & $105 \mathrm{AD}$ \\
\hline $\begin{array}{l}\text { Confidence ranges } \\
\text { calculated from } \\
\text { probability density } \\
\text { with probabilities }\end{array}$ & \begin{tabular}{|l|}
$68.26 \%$ \\
$94.44 \%$ \\
\end{tabular} & $\begin{array}{ll}69-135 \mathrm{AD} & (100 \%) \\
28-42 \text { AD } & (2.8 \%) \\
51-212 \mathrm{AD} & (97.2 \%)\end{array}$ & $\begin{array}{ll}69-135 \mathrm{AD} & (100 \%) \\
29-41 \mathrm{AD} & (2 \%) \\
52-212 \mathrm{AD} & (98 \%)\end{array}$ & $\begin{array}{r}72-130 \mathrm{AD} \\
26-42 \mathrm{AD} \\
52-150 \mathrm{AD} \\
156-212 \mathrm{AD} \\
\end{array}$ & \\
\hline \begin{tabular}{|c} 
Confidence ranges \\
calculated from \\
cumulative \\
probability \\
\end{tabular} & $\begin{array}{l}50.00 \% \\
68.26 \% \\
95.44 \% \\
98.00 \% \\
\end{array}$ & $\begin{array}{l}85-128 \mathrm{AD} \\
75-150 \mathrm{AD} \\
32-207 \mathrm{AD} \\
25-215 \mathrm{AD} \\
\end{array}$ & & & $\begin{array}{l}86-125 \mathrm{AD} \\
37-204 \mathrm{AD} \\
28-214 \mathrm{AD} \\
\end{array}$ \\
\hline
\end{tabular}

*This result was published in the comparison of calibration methods (Aitchison et al. 1989).

**van der Plicht, Mook and Hasper (1987) results of the peak analysis can be compared with our 3 o ranges (99.7\%).

${ }^{\dagger}$ This result was published in the discussion of van der Plicht, Mook and Hasper (1987). 


\section{REFERENCES}

Aitchison, T. C., Leese, M., Mook, W. G., Otlet, R. L., Ottaway, B. S., Pazdur, M. F., van der Plicht, J., Reimer, P. R., Robinson, S. W., Scott, M., Stuiver, M., Walker, J. and Weninger, B. 1989 Comparison methods used for the calibration of Radiocarbon. In Long, A., and Kra, R. S., eds., Proceedings of the 13th International ${ }^{14} \mathrm{C}$ Conference. Radiocarbon 31(3): 846-864.

Bayes, T. 1958 (1763) An essay towards solving a problem in the doctrine of changes. Biometrika 45: 293-315 (reprint of 1763 version).

Bonani, G., Ivy, S., Wölfli, W., Broshi, M., Carmi, I. and Strugnell, J. 1992 Radiocarbon dating of fourteen Dead Sea scrolls. Radiocarbon, this issue.

Eadie, W. T., Dryard D., James, F. E., Roos, M. and Sadoulet, B. 1971 Statistical Methods in Experimental Physics. North-Holland Publishing Co.: 17-23.

Fischlin, A. 1986 The DialogMachine for the Macintosh. Project-Centre (IDA), Internal Report, Swiss Federal Institute of Technology, ETH Zürich.

Digital 1988 Desktop Release 3.1, Digital Research (UK) Limited, Oxford House, Oxford Street, Newbury, Berkshire, RG131JB.

Keller, D. 1989 Introduction to the DialogMachine. Projekt-Zentrum (IDA), Internal Report 5, Swiss Federal Institute of Technology, ETH Zürich.

Lanting, J. N. and Mook, W. G. 1977 The Prehistory of The Netherlands in Terms of Radiocarbon Dates. Groningen, Groningen University Press.

Michczynska, D. J., Pazdur, M. F. and Walanus, A., ms, Bayesian approach to probabilistic calibration of radiocarbon ages. In Mook, W. G. and Waterbolk, H. T., eds., Proceedings of the 2nd International Symposium on Archaeology and ${ }^{14}$ C. PACT 29-II.4.

Mook, W. G. $1983{ }^{14} \mathrm{C}$ calibration curves depending on sample time width. In Waterbolk, H. T. and Mook, W. G., eds., Proceedings of the Symposium on ${ }^{14} \mathrm{C}$ and Archaeology. PACT 8: 517-525.

Mook, W. G., Hasper, H. and Plicht, J. van der 1987 Background and procedures of ${ }^{14} \mathrm{C}$ calibration. In Aurenche, O., Evin, J. and Hours, F., eds. 1987 Chronologies in the Near East. CNRS International
Symposium. BAR International Ser. 379(i): 145-150.

Pazdur, M. F. and Michczynska, D. J. 1989 Improvement of the procedure for probabilistic calibration of radiocarbon dates. In Long, A. and Kra, R. S., eds., Proceedings of the 13 th International ${ }^{14} \mathrm{C}$ Conference. Radiocarbon 31(3): 824-832.

Pearson, G. W. and Stuiver, M. 1986 High-precision calibration of the radiocarbon time scale, 500-2500 BC. In Stuiver M. and Kra, R. S., eds., Proceedings of the 12th International ${ }^{14} \mathrm{C}$ Conference. Radiocarbon 28(2B): 839-862.

Pearson, G. W. , Pilcher, J. R., Baillie, M. G. L., Corbett, D. M. and Qua, F. 1986 High-precision ${ }^{14} \mathrm{C}$ measurement of Irish oaks to show the natural ${ }^{14} \mathrm{C}$ variations from $A D$ 1848-5210 BC In Stuiver, M. and Kra, R. S., eds., Proceedings of the 12th International ${ }^{14} \mathrm{C}$ Conference. Radiocarbon 28(2B): 911- 934.

Plicht, J. van der and Mook, W. G. 1989 Calibration of radiocarbon ages by computer. In Long, A. and Kra, R. S., Proceedings of the 13 th International ${ }^{14} \mathrm{C}$ Conference. Radiocarbon 31(3): 805-816.

Reimer, P. J. and Stuiver, M. 1987 User's Guide to the Program Calib and Display Rev 2.1. Quaternary Isotope Lab, University of Washington.

Stuiver, M. and Pearson, G. W. 1986 High-precision calibration of the radiocarbon time scale, AD 1950500 BC. In Stuiver, M. and Kra, R. S., eds., Proceedings of the 12 th International ${ }^{14} \mathrm{C}$ Conference. Radiocarbon 28(2B): 805-838.

Stuiver, M. and Reimer, P. J. 1986 A computer program for radiocarbon age calibration. In Stuiver, $M$. and $\mathrm{Kra}, \mathrm{R}$. S., eds., Proceedings of the 12th International ${ }^{14} \mathrm{C}$ Conference. Radiocarbon 28(2B): 1022-1030.

TopSpeed Modula-2 1989-1990 Jensen and Partners International, The Turnmill, G3 Clerkenwell Road, London, EC 1M5NP.

Wirth, N. 1988 Programming in Modula-2, 4th ed. Berlin, Springer Verlag.

Wirth, N., Gutknecht, J., Heiz, W., Schär, H., Seiler, H., Vetterli, C. and Wolf, T. 1989 MacMETH User Manual. Dept Informatik, ETH Zürich. 